\title{
Strength of composite plate with parallel offset misalignment double- bolted joint under bending moment
}

\author{
Narongkorn Krajangsawasdi ${ }^{1}$, a and Phacharaporn Bunyawanichakul ${ }^{1}$ \\ ${ }^{1}$ Design Clinic Research Unit, Department of Aerospace Engineering, Faculty of Engineering, Kasetsart University, 50 Ngam Wong Wan \\ Rd., Ladyaow, Chatuchak, Bangkok, 10900, Thailand
}

\begin{abstract}
The connection concept of placing only two bolts in offset misalignment against the bending load along the wing span was used for an aerobatic airplane designed in Thailand as a KIT plane to minimize the impact of drilling numerous holes. This concept can deviate the force direction on the holes. The two suitable drilling positions should have the lowest resultant force and highest strength of fiber reinforcement structure. To investigate the strength of the fastener hole when the force deviated from the original orientation, specimens, made from twill weave carbon fiberepoxy and laid up at \pm 45 -degree orientation, were tested under bearing load according to ASTM D5961 standard. The experimental results revealed that the bearing strength of CFRP material decreases when the force deviation angle increases, so zero-angle deviation of the resultant force on the drilling hole is the most suitable orientation to absorb bolt bearing load. The most suitable pattern of two offset misalignment holes is the greatest horizontal distance at zero vertical distance when it was considered only the effect of the bearing strength and the deviation angle. Moreover, the failure pattern begins to deviate along the fiber orientation when the inclination angle increased.
\end{abstract}

\section{Introduction}

The parallel offset misalignment bolt joint is an interesting concept. It is applied to some KIT planes fixture such as Lancair Legacy (Figure 1) [1] and FURIO (Figure 2) [2]. The KIT plane concept allows customers of KIT planes or Experimental Light Sport Aircraft to assemble more than 50 percent of the overall aircraft components themselves. This facilitates delivery to buyers by separate parts, especially such large parts as the wing spar which is the focus of this paper. The concept considered here is called Torsional Resistance of the Bolt Group, and it uses two bolts to connect the left and right wings. The concept can counter the bending moment that plays an important role in the lift force on the wing. Every structure is always weakened by drilling holes, especially composite structure which is composed of a fiber fabric and resin matrix. Its strength depends on the direction of the fiber fabric. Therefore, the minimum number of bolts is two, this is considered suitable and safe regarding the fabric structure and drilling holes and supporting the wing load. The bolt fixing pattern and the load action on the structure considered in the current paper is illustrated in Figure 3.

There are three primary failure modes in a plate with a fastener hole when a bearing load is applied: local bearing, net tension, and shear out [3]. Figure 4 illustrates the different failure modes for the three failure patterns. It can be seen that the local bearing is the only a pattern which cannot break the whole structure, so it is defined as

\footnotetext{
${ }^{a}$ Corresponding author: narongkorn.k@ku.th
}

non-catastrophic failure, whereas the others are in the catastrophic group. The graph between load and deflection of a hole can be plotted in order to indicate the difference load absorption between catastrophic and noncatastrophic.

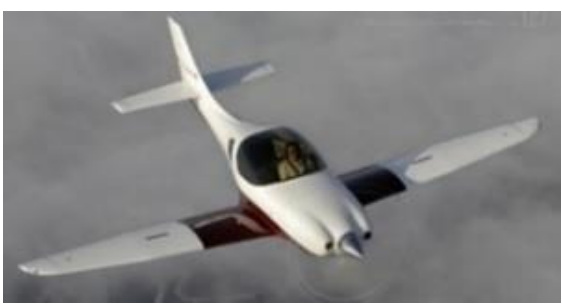

Figure 1. Lancair Legacy [1]

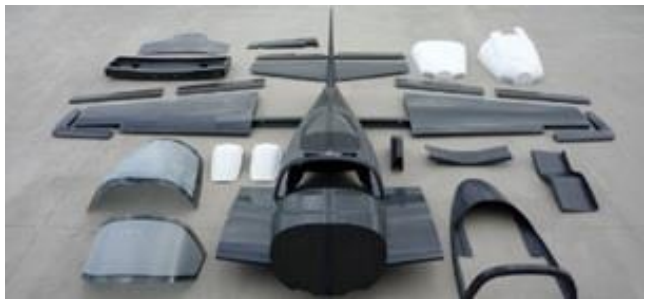

Figure 2. Unassembled FURIO 2 [2].

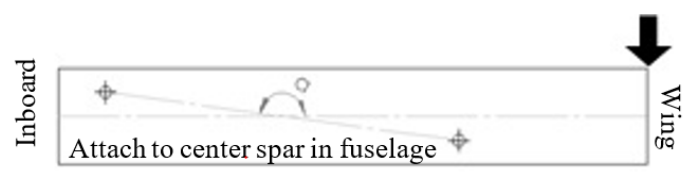

Figure 3. Double bolted fixed pattern with bending load generated by the vertical force. 

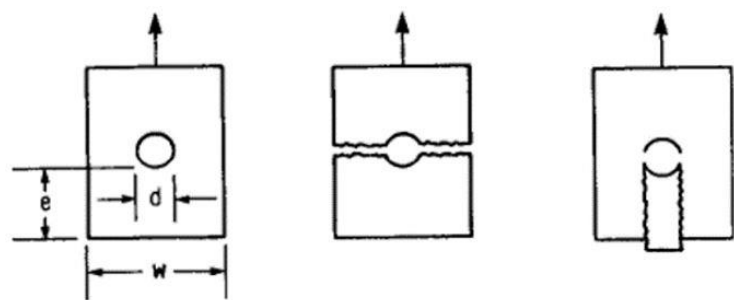

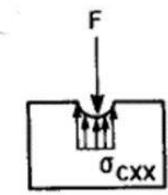

Local bearing

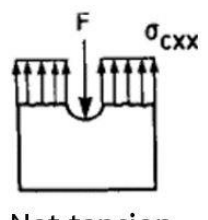

Net-tension

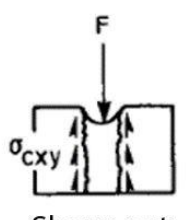

Shear-out
Figure 4. Three major failure modes of plate with a fastener subject to bearing load [3].

Figure 5 [4] shows local bearing failure which consists of a long zig-zag region between the yield point and the ultimate load. It can be implied that the hole is compressed and reformed after the compressed load, so it can absorb more load. Obviously, large hole deflection occurs. By contrast, the catastrophic failure graph in Figure 6 [4] has a short zig-zag region. After this zone, the acting load decreases rapidly because the broken plate cannot resist any load.

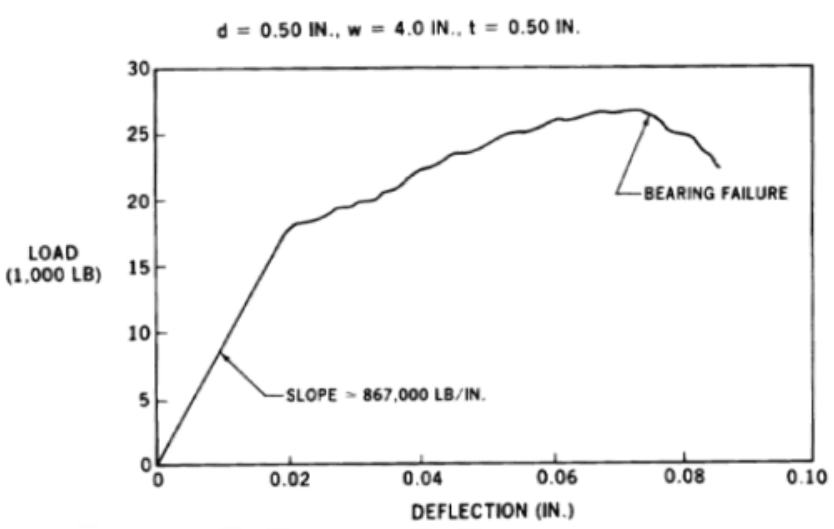

Figure 5. Non-catastrophic failure when the plate subjects to the bearing load (load-deflection graph) [4].

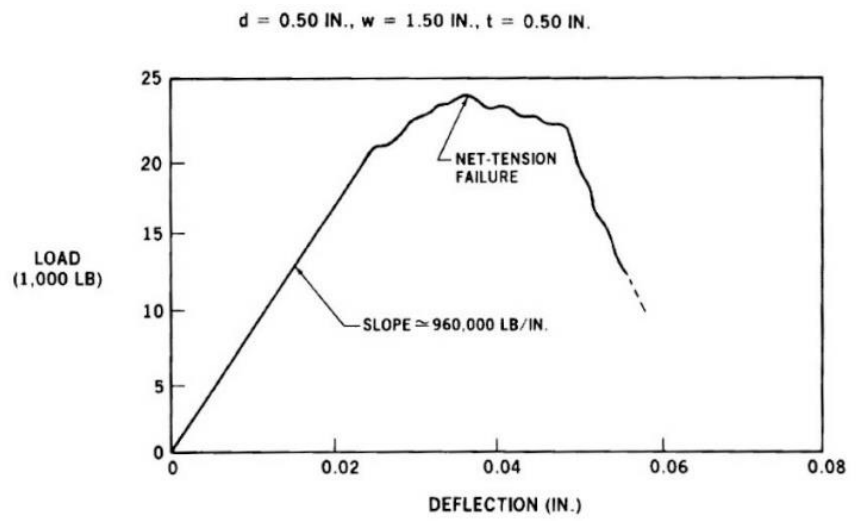

Figure 6. Catastrophic failure when the plate subjects to the bearing load (load-deflection graph) [4].
A number of researchers studying a composite plate with fastener holes usually define which mode is the most dominant. To avoid the catastrophic failure mode (including net tension and shear out which will occur when the plate is too narrow compared with the hole and the hole is too near the edge), many studies have attempted to define the safe size of the plate, especially the width and edge distance. Some researchers $[5,6]$ have claimed that the suitable plate width is around 2.5-4 times the hole diameter and the suitable distance from the edge to the hole center should be around 4 times the hole diameter. In addition, some research focused on analytical methods to define the failure modes. Characteristic curve method is a analytical theory which combines the hole failure modes with composite failure criterion has been used to estimate the maximum load and identify the failure modes in hole specimen [7].

Torsional resistance on bolt group is a theory to compute the resultant force occurring on the drilled hole from a vertical load acting on the other side of bolt group. It is calculated by moving the force from located on one end to the center of the bolt group. It leads to a coupled bending moment acting on its center, so two load types act to the drilled holes the removed-vertical force and the couple moment [8]. They are combined using the vector computation method. Figure 7 illustrates the method for the calculation of the force on the drilling holes.

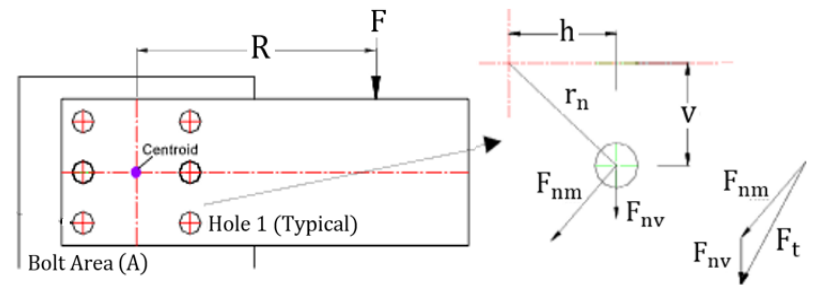

Figure 7. Diagram to calculate following the torsional resistance of bolted group [8].

A study [9] derived an equation for calculating the force acting on the double bolt using the torsional resistance bolt group theory. That paper varied the position of the drilling holes on the plate and calculated the force both from the vertical load and coupled moment. From this, the force can be plotted as a contour graph in which the $\mathrm{X}$ and $\mathrm{Y}$ distances shown by the vertical and horizontal axes, respectively, and the calculated force is the contour line. The force acting on the inner hole and the outer hole is illustrated in Figures 8 and 9. For example, when the $\mathrm{X}$ distance is $0.1 \mathrm{~m}$ and the $\mathrm{Y}$ distance is $0.01 \mathrm{~m}$, the force action to the inner and outer holes is approximately $1.33 \mathrm{~N}$ and $2.32 \mathrm{~N}$, respectively. It is evident that the resultant force on both holes gradually decreases when the distance between two holes is greater.

Due to the complexity and difficulty of generating the torsional resistance with the bending load, the experiment was simplified. The bending load causing the inclined compression load on the drilled holes was investigated using the bearing strength test following the ASTM standard on a hole drilled in Carbon Fiber Reinforced Polymer (CFRP) plates with the deviated ply orientation. 


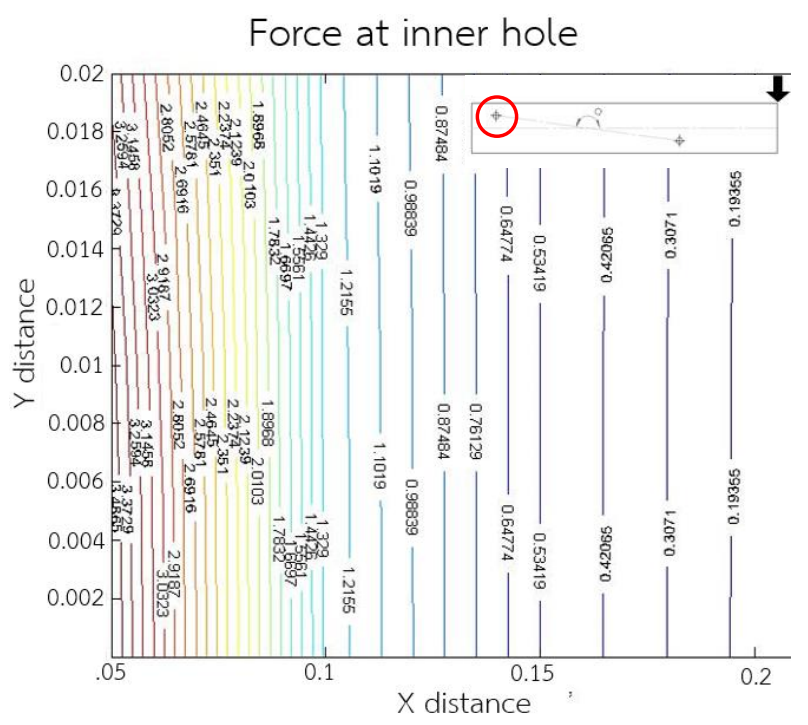

Figure 8. Force contour acting on the inner hole of the spar web with two fastening holes in offset misalignment [9].

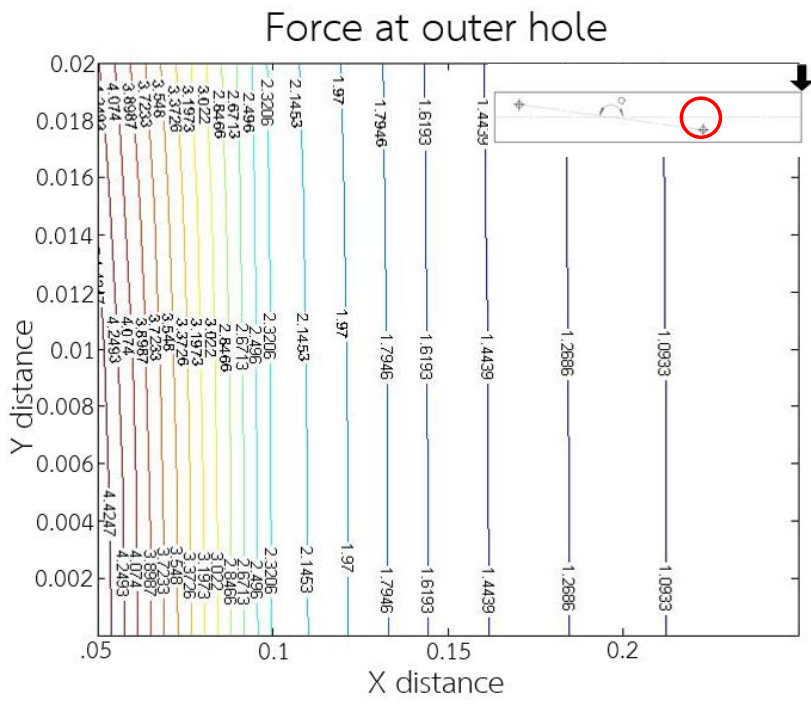

Figure 9. Force contour acting on outer hole of the spar web with two fastening holes in offset misalignment [9].

The fastener bolt hole experiment complied with the ASTM D5961 Procedure A standard [10]. The sizing of the specimen recommended in the standard is that the coupon should have a 0.25 in $(6.35 \mathrm{~mm}$ diameter $)$ hole with $19 \mathrm{~mm}$ distance from the nearest edge to the center and it should be cut to $140 \mathrm{~mm}$ long and $38 \mathrm{~mm}$ wide. Figure 10(a) provides an illustration of the recommended specimen sizing.

According to ASTM D5961 Procedure A, the testing specimen is clamped with a bolt to a double-lapped metal plate as shown in Figure 10(b).

Vangrimde and Boukhili [11] presented a method to measure the deformation of the drilling hole after it is drawn by the bolt. As can be seen in Figure 11, two Linear Variable Displacement Transformers (LVDT) are attached to the fixture and their probes touch the reference that pulls out the specimen. This procedure can eliminate the tensile plate displacement and focus on only the hole displacement.

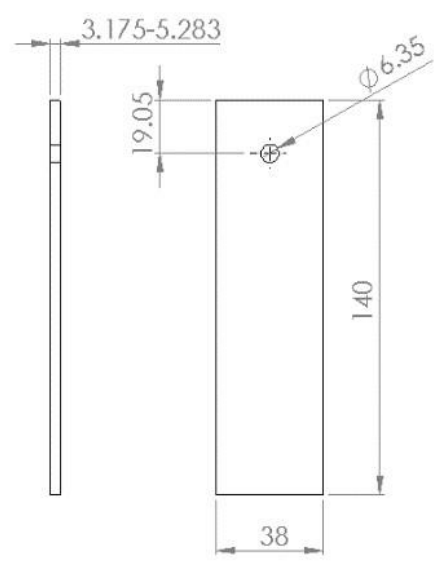

(a)

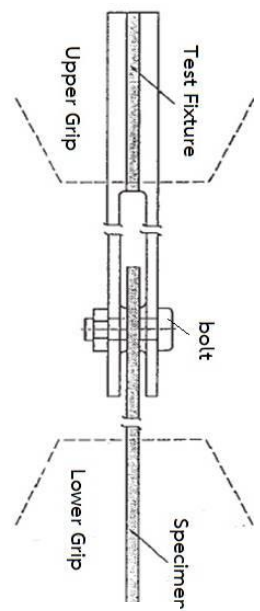

(b)
Figure 10. (a) Specimen dimension according to bearing test (ASTM D5961), (b) specimen with a bolt installation according to ASTM D5961 standard [10].

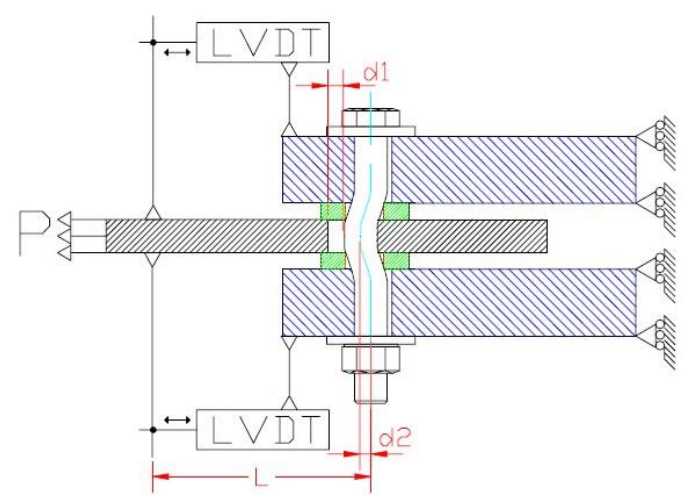

Figure 11. Vangrimde and Boukhili procedure to measure the hole displacement by the relation deformation of the specimen and the fixture using LVDT attached to the testing fixture [11].

Although the failure mode of a hole in the composite material has been studied in many fields, there is no research which focuses on the failure mode of composite plate fixing as a bolt group with the parallel offset misalignment concept. The acting load will deviate from the principle strength direction in the fabric. The current research investigated the bearing strength of the hole acting by using a simulated load of bending on the offset misalignment bolt group to a single force with the deviation angle on the hole. Consequently, the experiment was set up by testing carbon fiber-epoxy coupons with a different ply orientation according to the force deviation by the bending load following the ASTM standard.

\section{Methodology}

\subsection{Specimen Lamination}

According to ASTM D5961 Procedure A [10], the plates were fabricated using carbon fiber fabric twill $2 \times 2$ and EPOTEC YD $535 \mathrm{LV} / \mathrm{TH} 7253-8$. Each lamina is 0.25 $\mathrm{mm}$ thick, so 14 layers of the coupon were laid in the 
same direction in order to obtain sufficient thickness for the bearing test following a vacuum infusion process under minus 1 bar-pressure. After fabrication, the plates were air cured for 24 hours. In order to provide greater accuracy on the degree orientation, which is a significant factor in this study, the plates were cut using CNC milling machine into $38 \mathrm{~mm} \times 140 \mathrm{~mm}$ coupons with the different angles. Six sets of different angles were investigated $(0,5,10,15,20$, and 25 degree-deviation) as shown in Figures 12 and 13. The thickness of the coupons are in the range of $3.5 \pm 0.05 \mathrm{~mm}$.

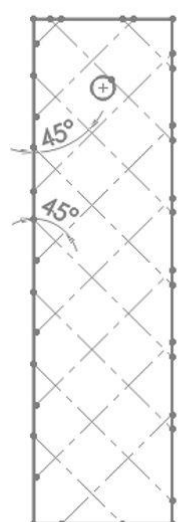

(a)

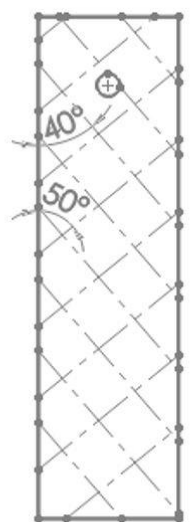

(b)

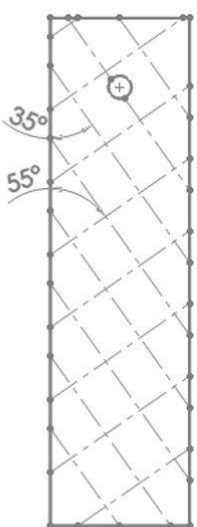

(c)
Figure 12. Drawing of samples after cured cutting with inclined angle (from \pm 45 degree) of (a) 0 degrees, (b) 5 degrees, and (c) 10 degrees.

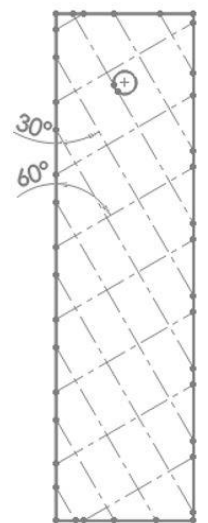

(a)

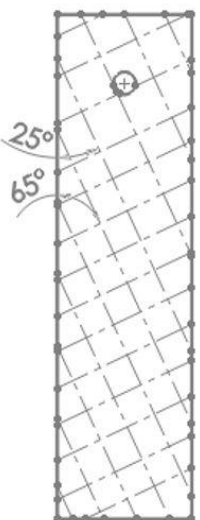

(b)

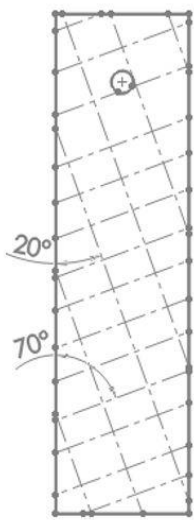

(c)
Figure 13. Drawing of samples after cured cutting with inclined angle (from \pm 45 degree) of (a) 15 degrees, (b) 20 degrees, and (c) 25 degrees.

\subsection{Test Fixture}

To comply with the ASTM standard mentioned above, a static tension load was applied to the coupon using a universal testing machine with tensile grips and a special fixture for the bearing test. The fixture was designed in the same manner as SACMA SRM 9-89 [12]. However, the standard gripping head of the testing machine is often too narrow (about $25 \mathrm{~mm}$ ) to install the coupons following ASTM D5961. Therefore, the adaptor was modified to be able to clamp the $38-\mathrm{mm}$ width coupon and to adjust the load alignment through the center of the machine head. The manufactured fixture and adaptor are illustrated in Figures 14 and 15.

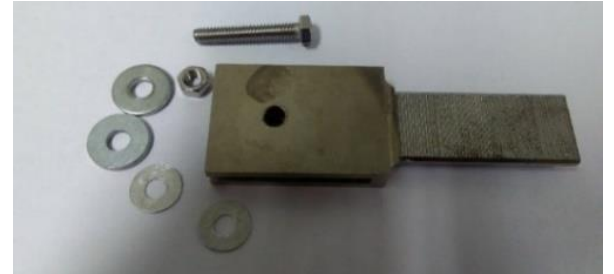

Figure 14. Specimen fixture with a bolted hole according to SACMA SRM 9-89 fixture.

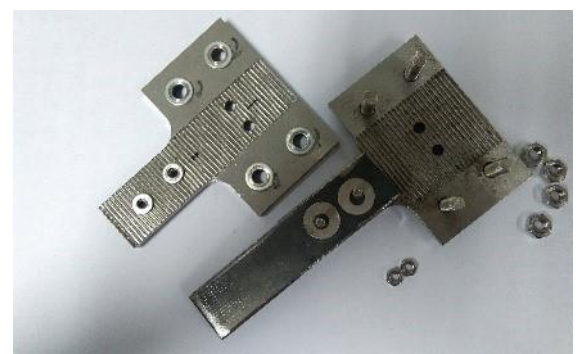

Figure 15. Adaptor for $38-\mathrm{mm}$ width specimen and the $25-\mathrm{mm}$ testing machine gripper.

\subsection{Stress-strain measurement procedure}

Due to coupling of the other extension portions in the coupon during the test following the Vangrimde and Boukhili procedure [11], a method to measure only the hole deformation is proposed. The extensometer is attached to the coupon in the zone next to the hole in order to measure the tensile extension of the coupon when the tensile load from the universal test machine is applied. As the gauge range is $25 \mathrm{~mm}$, the total tensile deformation could be calculated by interpolation. Then, the hole deformation $\left(\delta_{\mathrm{L}}\right)$ can be computed by deducting the tensile deformation (from the extensometer) from the total deformation (from the testing machine head). A diagram and all installation components including a sample are illustrated in Figure 16. The INSTRON universal testing machine and INSTRON extensometer $25 \mathrm{~mm}$ were used in this experiment. The load was applied in a displacement control protocol with 1 $\mathrm{mm} / \mathrm{min}$.

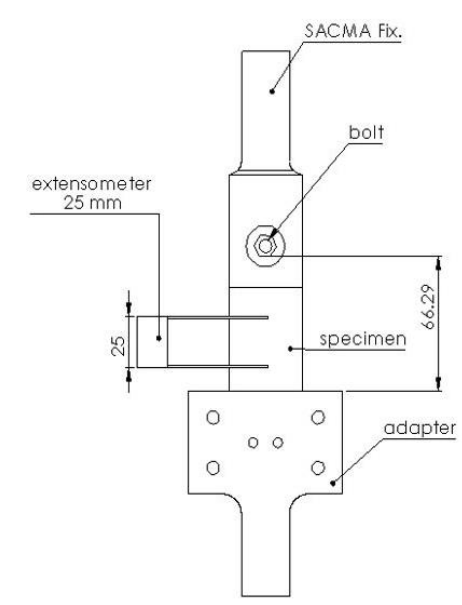

(a)

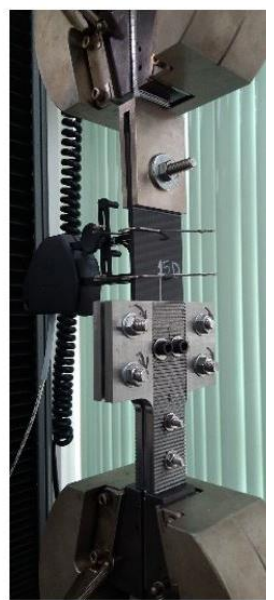

(b)
Figure 16. (a) Testing component schematic including SACMA fixture, specimen with a hole, adaptor, and the extensometer and (b) the actual installation to the INSTRON universal testing machine. 


\subsection{Bearing stress-strain calculation}

Load-displacement curves obtained from the specific test using a CFRP plate were recorded. According to ASTM D5961 [10], the bearing stress $\left(\sigma_{\mathrm{br}}\right)$ and bearing strain $\left(\varepsilon_{\mathrm{br}}\right)$ can be calculated using equation (1) and (2), respectively.

$$
\begin{gathered}
\sigma_{b r}=\frac{P}{D \times t} \\
\varepsilon_{b r}=\frac{\delta_{L}}{D}
\end{gathered}
$$

When $\mathrm{P}=$ load reading from testing machine, $\mathrm{N}$

$\mathrm{D}=$ bolt hole diameter, $\mathrm{mm}$

$\mathrm{t}=$ plate thickness, $\mathrm{mm}$

$\delta \mathrm{L}=$ hole deformation (by LVDT), $\mathrm{mm}$

After the bearing stress-strain of each coupon was calculated, it was plotted to determine the bearing strength. The slope in the linear region of the stress-strain curve was defined as well as another linear curve, drawn by a $2 \%$ strain offset from the previous linear curve. The intersection of the bearing stress-strain curve from the experiment and the $2 \%$ offset line is called the offset strength which represents the yield strength of the hole. This point is known as the final stress limit of the structure. Figure 17 shows the bearing stress-strain and the method to determine the offset strength. Moreover, the slope of the plotted curve in the linear region is the bearing stiffness which is the mechanical properties of the laminate.

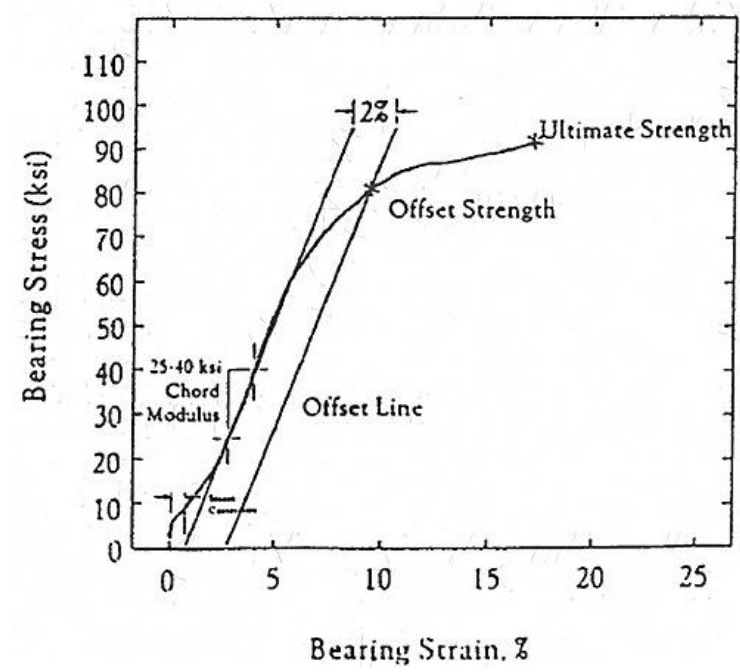

Figure 17. Bearing stress-strain test result analysis following ASTM D5961 to define offset strength, chord modulus, and ultimate strength [10].

\section{Result and Discussion}

\subsection{Bearing stress-strain curves}

After the load and displacement from the testing machine and extensometer were recorded, the bearing stress and bearing strain were computed by equation (1) and (2). There are two curves plotted on the graph. One has a larger strain which is calculated using the total strain measured with the testing machine. The other curve has the strain correction process that declines the strain. According to the elimination tensile extension approach, the corrected bearing strain was recalculated and plotted. Following this step, the $2 \%$ offset line was drawn on the corrected curve. The cutting point of the straight line and stress-strain curve is called offset strength. Figure 18 illustrated the example of data analysis. The darker line (0C total) is the raw data and the lighter line $(0 \mathrm{C}$ adj) is the strain correction data. Then, the dashed line (Linear (offset)) is drawn to determine an intersection point between it and the strain collection curve in order to define the offset strength of the hole. It can be seen that the slope of the stress-strain curve increases because the tensile strain is eliminated, and the strain is computed from only the hole deformation. However, the stress level after strain correction remains the same.

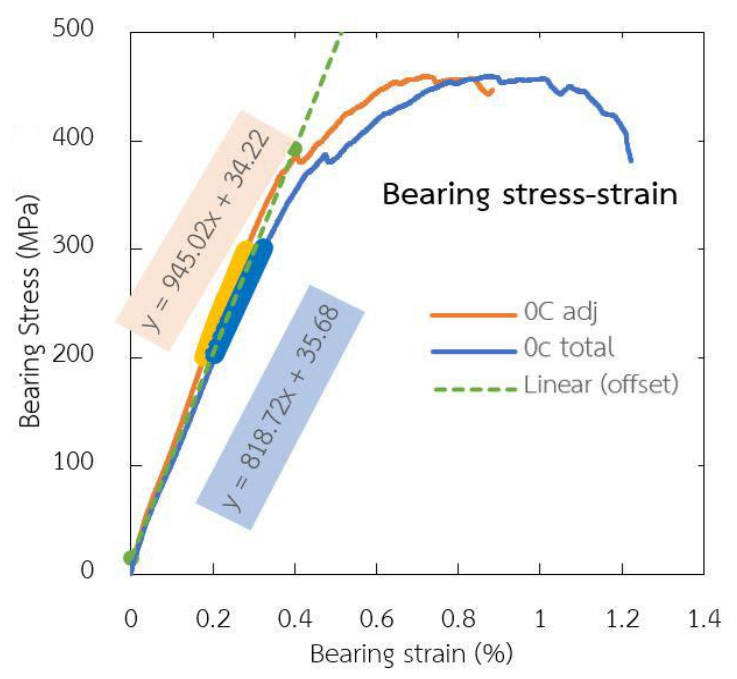

Figure 18. Bearing stress-strain curve obtain from the machine before (blue line) and after (orange line) bearing strain correction.

The stress-strain curves of three coupons for each deviation angle are shown in Figures 19 to 24. The three curves have a similar stiffness for the same deviation angle; the slope difference is less than $5 \%$ for each sample type. Thus, it can be implied that the bearing stiffness of each angle is similar. Because of the small deviation angles increase at 5 degrees per step, the bearing stiffness or slope of the curve for different deviation angles remains in a range (between 800 and $1100 \mathrm{MPa}$ ). Hence, the cutting point of every offset line should be at a similar stress level (around 350-450 MPa). Clearly, there are multiple peaks along each curve and every peak point refers to the maximum force that compresses the hole until it cannot bear and fail. As the strain increases, the CFRP material around the hole forms a new structure by the compression load and then it can absorb more load due to the natural inhomogeneity of the plate. It can bear the load until other damage failure (except bearing failure) occurs in the structure and it shows at the highest peak on the curves. 


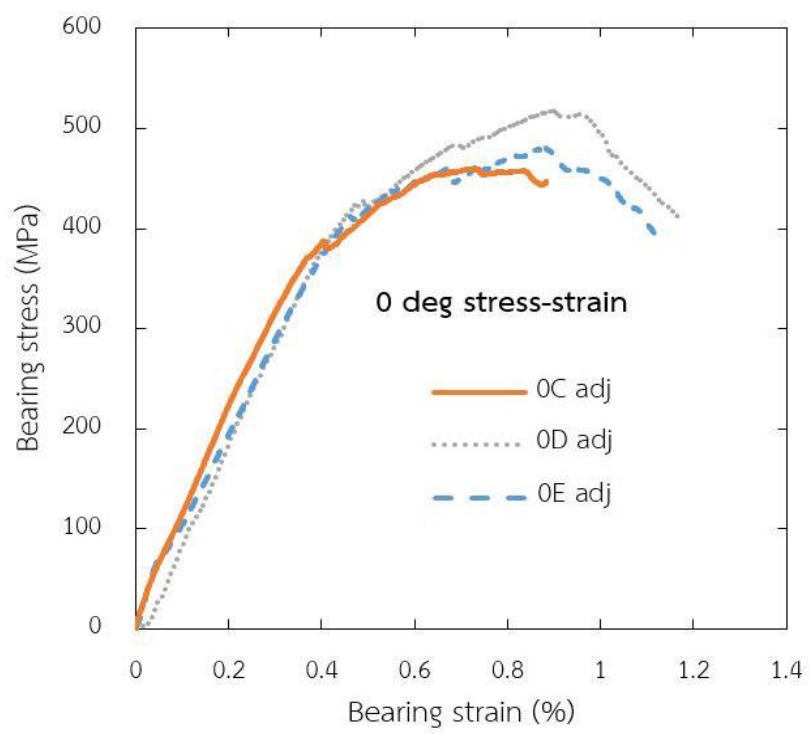

Figure 19. 0-degree inclination bearing stress/bearing strain test result after bearing strain correction.

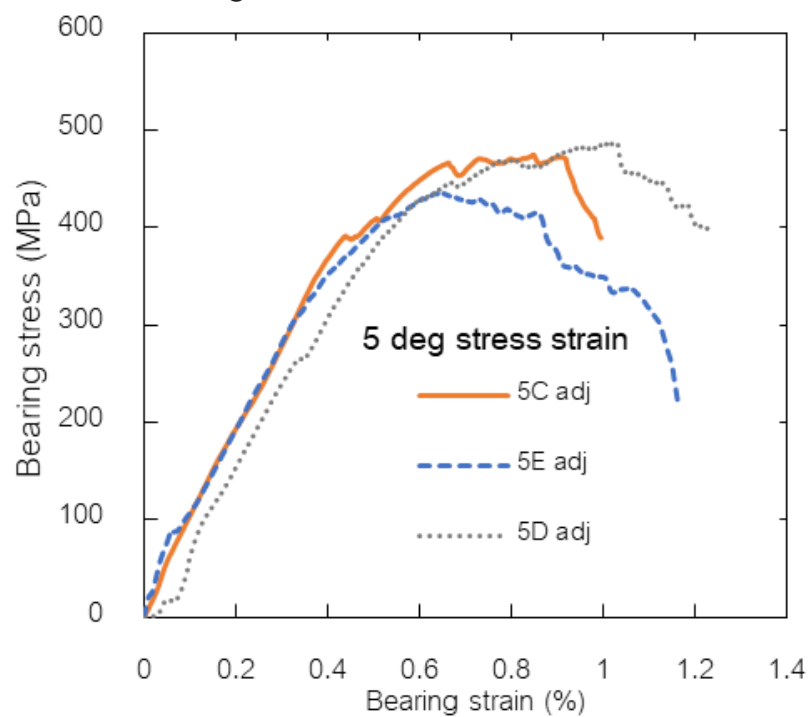

Figure 20. 5-degree inclination bearing stress/bearing strain test result after bearing strain correction.

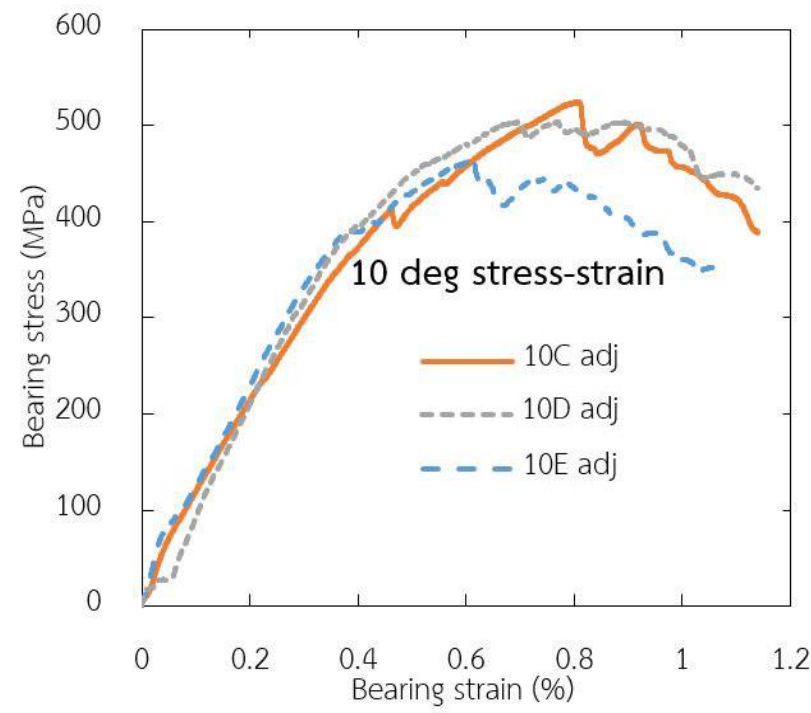

Figure 21. 10-degree inclination bearing stress/bearing strain test result after bearing strain correction.

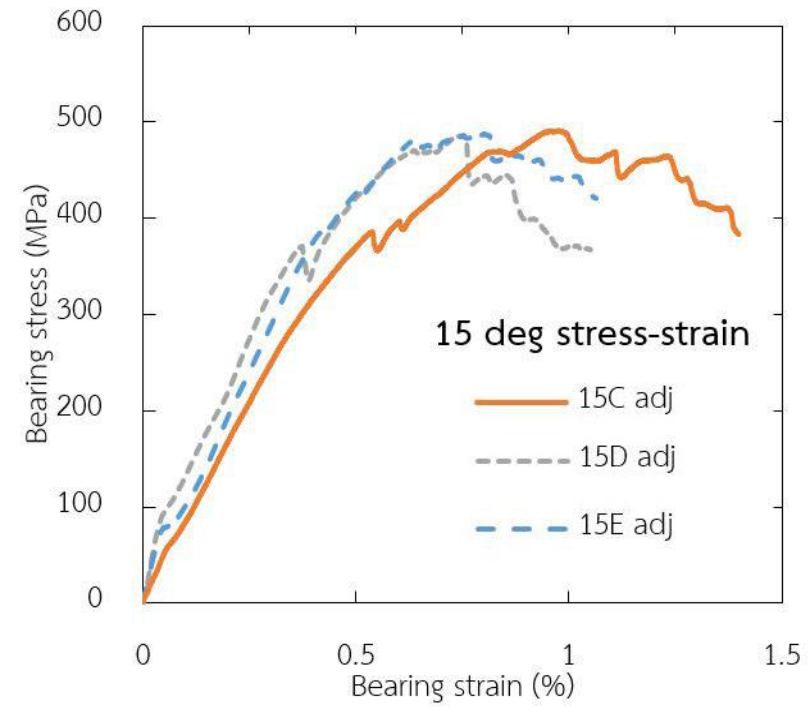

Figure 22. 15-degree inclination bearing stress/bearing strain test result after bearing strain correction.

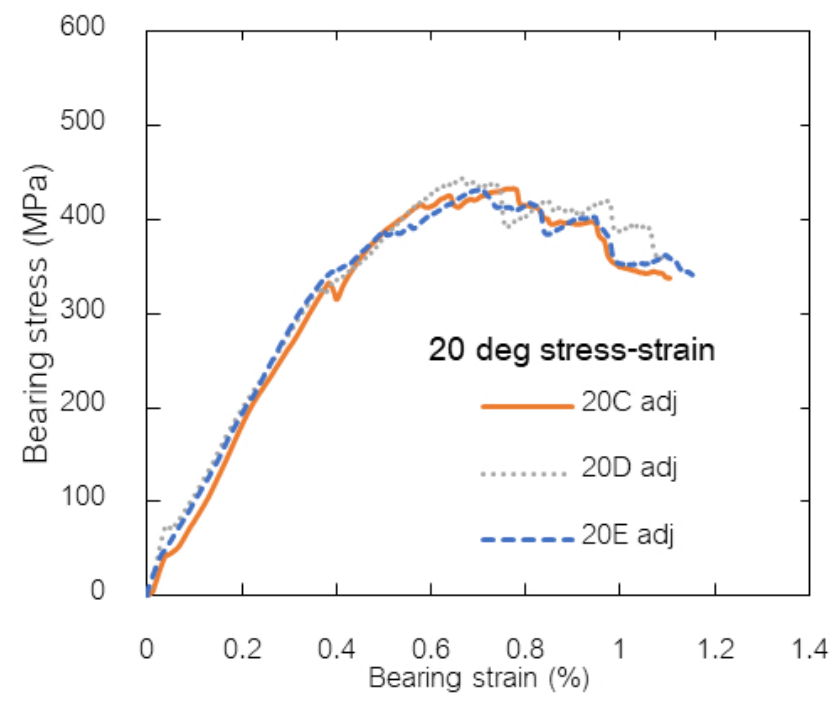

Figure 23. 20-degree inclination bearing stress/bearing strain test result after bearing strain correction.

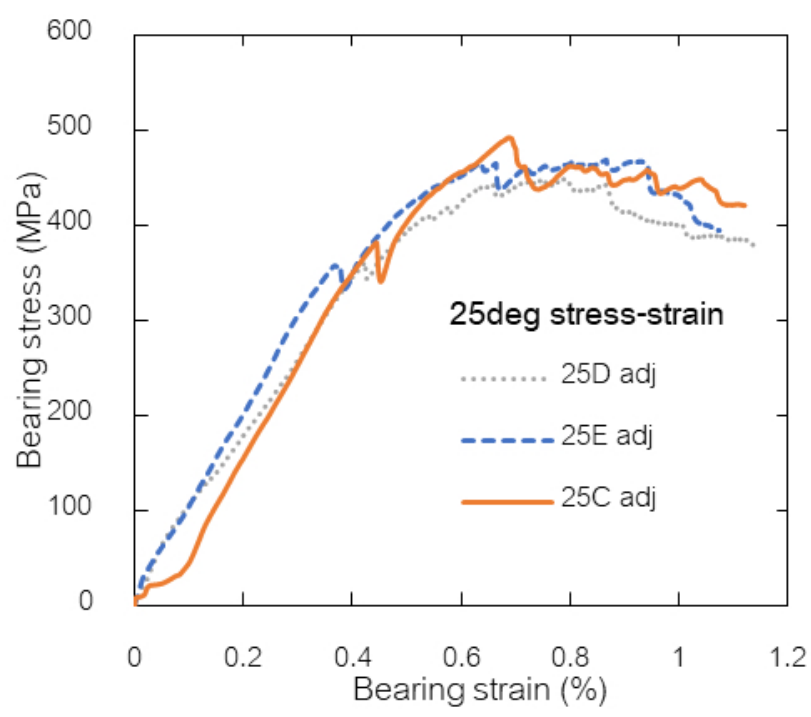

Figure 24. 25-degree inclination bearing stress/bearing strain test result after bearing strain correction. 
Offset strength relation

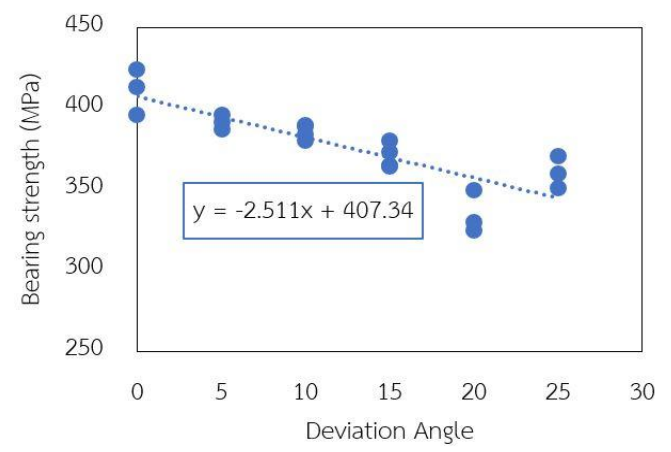

Figure 25. Offset strength result of each specimen and the linear regression equation.

\subsection{Strength analysis}

According to Figure 25, the offset strength seems to decrease when the deviation angle increases. Whereas the strength of 20-degree group remarkably declines. This may be because of a defect in the manufacturing process that caused this group to have a lower weight (approximately 1g) than other groups. The declination of strength can be interpreted by the resultant force in the fiber. As can be seen in Figure 26, the inequality between angles 1 and 2 results in some deviations in fiber direction. Thus, the bearing load in the vertical direction, which is distributed to both fibers, divides into two fibers unequally as can be seen in Table 1 . The combination of force in two directions, which represents the capability to bear the amount of force on the structure, reveals that the resultant force of the larger deviation angle is lower than for the smaller deviation angle. This can be interpreted as the larger deviation angle results in a weaker structure because it diminishes the ability to absorb the total force acting on the hole. This is one of several reasons why the experimental results show the declination in bearing strength when there is a rise in the deviation angle.

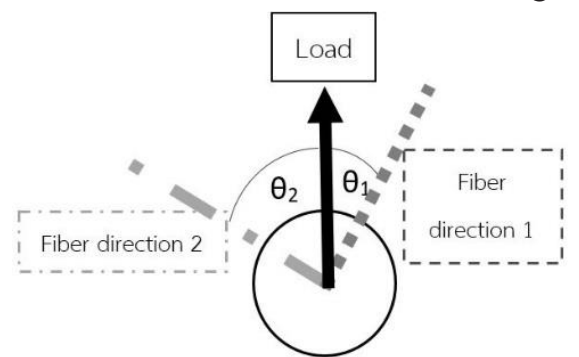

Figure 26. Schematic of two fiber directions in the woven fabric which deviated and subjected to the axial load.

Table 1. Inclination angle of fiber with the resultant force distributed to each direction.

\begin{tabular}{|c|c|c|c|c|c|}
\hline $\begin{array}{c}\text { Incline } \\
(\mathbf{d e g})\end{array}$ & $\begin{array}{c}\boldsymbol{\theta}_{\mathbf{1}} \\
(\mathbf{d e g})\end{array}$ & $\begin{array}{c}\boldsymbol{\theta}_{\mathbf{2}} \\
(\mathbf{d e g})\end{array}$ & $\cos \boldsymbol{\theta}_{\mathbf{1}}$ & $\cos \boldsymbol{\theta}_{\mathbf{2}}$ & $\begin{array}{c}\text { Resultant } \\
(\mathbf{N})\end{array}$ \\
\hline 0 & 45 & 45 & 0.707 & 0.707 & 1.41 \\
\hline 5 & 40 & 50 & 0.766 & 0.642 & 1.42 \\
\hline 10 & 35 & 55 & 0.819 & 0.573 & 1.39 \\
\hline 15 & 30 & 60 & 0.866 & 0.5 & 1.36 \\
\hline 20 & 25 & 65 & 0.906 & 0.422 & 1.32 \\
\hline 25 & 20 & 70 & 0.939 & 0.342 & 1.281 \\
\hline
\end{tabular}

\subsection{Failure pattern}

The comparison between 0-degree and 25-degree specimens showed a remarkable difference in hole failure. The hole deformation of 0 -degree deviation $( \pm 45$ degree ply orientation) was in the same direction as the acting force and the deformation gradually inclined with an increase in the deviation angle. The damage developed from the contact point between the bolt and specimen. This could then propagate along the fiber direction to the structural limit and lead to catastrophic failure. The assumption involved in this phenomenon is that the damage runs though the weaker direction which for the fiber is in the lateral direction. Figures 27 and 28 compare the specimens without and with inclination angle. The specimens without inclination angle can distribute force to both fibers equally resulting in the failure running straight along the force direction, but the specimens with an inclination ply angle (so that the fibers are aligned in the longitudinal direction) have greater strength, so the initial damage occurs in another direction. This phenomenon can be described by Figure 29.
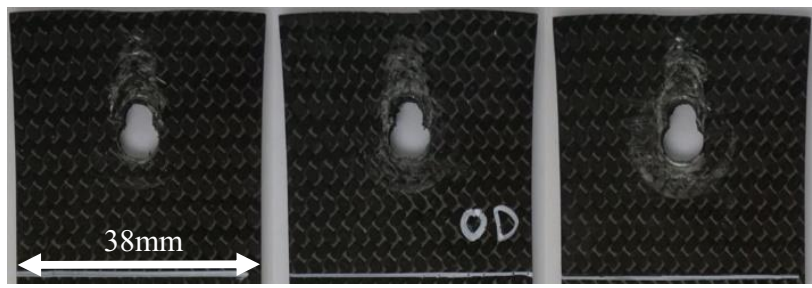

Figure 27. 0-degree deviation specimens' failure.
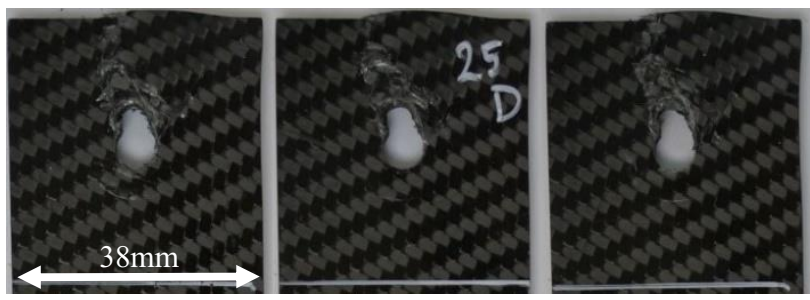

Figure 28. 25-degree deviation specimens' failure.

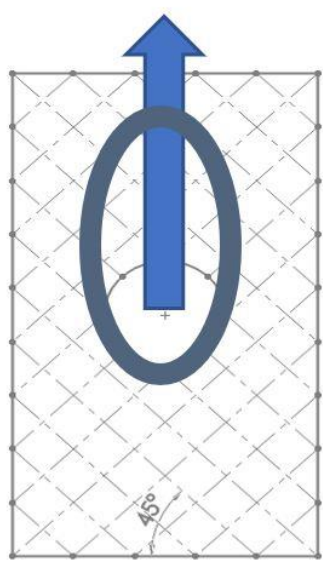

(a)

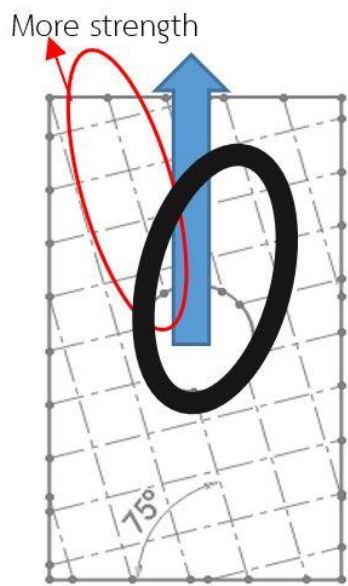

(b)
Figure 29. Schematic of failure mode with the fiber direction (a) 0-degree deviation angles and (b) 20-degree deviation angles. 


\subsection{Suitable drilling between holes}

The wing spar fixture area is limited at the root zone. The possible drilling point was defined in a study [9] mentioned in the previous section. That paper presented a given resultant force on each hole's horizontal (X) and vertical (Y) coordinates which deviate from the lamination direction of the wing spar which normally consists of 45-degree lay-up woven fabrics. Following this, the inclined angle of the force acting on the drilling hole can be extracted from that study and the bearing strength of the CFRP in the deviation force direction can be computed from the linear relationship of the inclined angle and bearing strength in Figure 25. The most suitable points to drill two fastening holes are at the coordinates that give the highest the strength to the resultant force of the two holes. Eventually, the coordinate that gives the highest ratio is at the maximum horizontal position without vertical direction as shown in Figure 30.

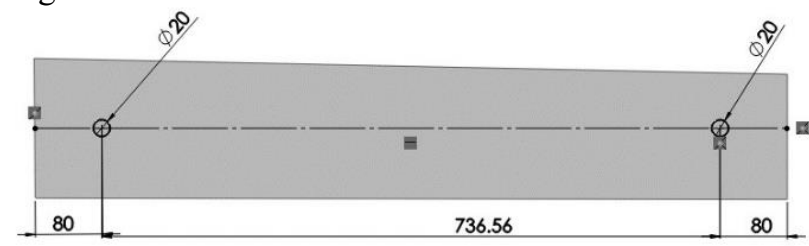

Figure 30. Suitable drilling hole positions after design considering the fiber inclination angle.

\section{Conclusion}

The bearing strength of the CFRP material when the force acts in the deviation angle from the setting orientation was determined by conducting an experiment following ASTM D5961. It was simplified by cutting the plate at an oblique angle instead of creating an inclination force. The results showed that the bearing strength of different deviation angles can linearly decrease when the inclination angle increases. This phenomenon can be explained by the force diagram that shows the deviation angle from cross-ply 45 degrees. The deviation angle reduces the ability to resist total force divided into each fiber direction which leads to a weakened structure. Moreover, the deviation angle makes the hole deformation deviate from the force direction because of the weakening in the direction that is not along the fiber axis. Eventually, a combination of the resultant force from the torsional resistance of bolt group equation and the linear relation between the inclined angle and bearing strength indicates the most suitable point to drill the fastening hole on the wing spar connection. The horizontal distance at the maximum point and at zero vertical distance is the most suitable location for this type of load.

\section{References}

1. Lancair International. Center wing section installation, URL: http://lancair.com/docs-lancairlegacy, accessed on 1/06/2017 (2017)
2. Falcomposite. Furio $\ln 27$ RG, URL: www.falcom posite.co/furio-rg.php, accessed on 1/06/2017 (2017)

3. C.C. Chamis, Simplified procedures for designing composite bolted joints. Journal of Reinforced Plastics and Composites, 9, 614-626 (1990)

4. W.D. Nelson, B.L. Bunin and L.J. Hart-Smith, Critical joints in large composite aircraft structure. Technical report, McDonnell Douglas Corp (1983)

5. M.H. Ahmad, A.D. Crocombe and P.A. Smith, Failure modelling of woven GFRP bolted joints under quasi-static loading. International Journal Integrated Engineering, 5, 2 (2013)

6. J. Ekh, Multi-fastener single-lap joints in composite structures. Ph.D. Thesis, Royal Institute of Technology, Sweden (2006)

7. F.K. Chang, R.A. Scott and G.S. Springer, Strength of mechanically fastened composite joints. Journal of Composite Material. 16, 470-494 (1982)

8. Roymech, Strength of bolts withstanding torsion generated shear loading. URL: www.roymech.co.uk /Useful-Tables/Screws/Bolted-Joint.html, accessed on $1 / 06 / 2017$ (2017)

9. N. Krajangsawasdi and P. Bunyawanichakul, Analysis on optimal location of double-bolted joint with parallel misalignment subjected to eccentric load. $55^{\text {th }}$ Kasetsart annual conference, 436-442 (2017)

10. Departments and agencies of the department of defense, MIL-HDBK-5H: Metallic materials and elements for aerospace vehicle structures (1998)

11. B. Vangrimde and R. Boukhili, Bearing stiffness of glass fiber-reinforced polyester: influence of coupon geometry and laminate properties. Composite Structures, 58, 57-73 (2002)

12. Wyoming Test Fixtures Inc, SACMA bearing strength test (SACMA SRM 9-89). URL: www. wyomingtestfixtures.com/Products/h2.html, accessed on $1 / 06 / 2017$ (2017) 